\title{
INOVASI PENGEMBANGAN APLIKASI MULTIMEDIA PANDUAN SKRIPSI MENGGUNAKAN ADOBE FLASH CS6
}

\author{
Tito Sugiharto,S.Kom., M.Eng ${ }^{1)}$, Siti Muzayana ${ }^{2)}$ \\ 1,2), Teknik Informatika Universitas Kuningan \\ Jl Cut Nyak Dien No 36 A Cijoho Kabupaten Kuningan \\ Email : tito@uniku.ac.id ${ }^{l)}$
}

\begin{abstract}
Abstrak
Penelitian ini dibuat bertujuan untuk menghasilkan suatu aplikasi multimedia panduan Skripsi menggunanakan adobe flash CS6. Target penelitian yang ingin dicapai adalah adanya sebuah media informasi alternatif yang menarik dan mudah untuk dipahami mengenai panduan Skripsi di Fakultas Ilmu Komputer Universitas Kuningan. Penelitian ini akan membahas bagaimana merancang dan mengembangkan aplikasi multimedia panduan Skripsi menggunakan adobe flash CS6. Pada saat ini panduan Skripsi yang ada di Fakultas Ilmu Komputer Universitas Kuningan masih berupa buku. Media buku sebagai panduan Skripsi menjadi media tunggal dalam menyebarkan informasi mengenai panduan Skripsi. Media buku memiliki kekurangan sebagai media informasi panduan Skripsi, diantaranya adalah menjadi media yang kurang menarik untuk diperhatikan, masih sedikitnya mahasiswa yang menggunakan media buku sebagai media informasi untuk panduan Skripsi, pemahaman yang berbeda dari media buku, dan kesulitan dalam mengakses media buku sebagai panduan Skripsi. Oleh karena itu, untuk menyelesaikan permasalahan tersebut maka diperlukan sebuah inovasi dalam pengembangan aplikasi multimedia panduan Skripsi menggunakan adobe flash CS6. Diharapkan dengan adanya aplikasi tersebut dapat menarik dan mempermudah mahasiswa dalam mencari informasi mengenai panduan Skripsi di Fakultas Ilmu Komputer Universitas Kuningan. Proses pengujian dilakukan dengan menggunakan User Acceptance Test (UAT).
\end{abstract}

Kata Kunci : Inovasi, Aplikasi, Multimedia, Panduan Skripsi, Flash.

\begin{abstract}
This research was made aiming to produce a thesis multimedia application application using adobe flash CS6. The research target to be achieved is the existence of an interesting and easy alternative information media to understand about the Thesis guide at the Faculty of Computer Science, University of Kuningan.This research will discuss how to design and develop multimedia applications using Thesis guides using adobe flash CS6. At this time the Thesis guide in the Faculty of Computer Science at the University of Kuningan is still a book. Media books as a thesis guide become a single medium in disseminating information about Thesis guidelines. Media books have shortcomings as a Thesis guide information media, including being less attractive media to note, there are still few students who use book media as information media for Thesis guidance, different understandings of book media, and difficulties in accessing media books as Thesis guidelines.Therefore, to solve these problems, we need an innovation in developing multimedia applications for Thesis guides using adobe flash CS6. It is expected that the existence of these applications can attract and facilitate students in finding information about Thesis guidelines at the Faculty of Computer Science, University of Kuningan. The testing process is carried out using the User Acceptance Test (UAT).
\end{abstract}

Keywords: Innovation, Application, Multimedia, Thesis Guide, Flash.. 


\section{PENDAHULUAN}

Universitas Kuningan (UNIKU) didirikan sebagai bentuk perwujudan dari idealisme dan komitmen Yayasan Pendidikan Sang Adipati Kuningan untuk terus menerus berkarya khususnya dalam bidang peningkatan Sumber Daya Manusia yang unggul dan maju. Universitas Kuningan saat ini memiliki 5 Fakultas, 3 Program Pasca Sarjana, 13 Program Studi S1 dan 2 Program Studi D3.

Salah satu Fakultas yang ada di Universitas Kuningan adalah Fakultas Ilmu Komputer. Fakultas Ilmu Komputer memiliki 5 Program Studi diantaranya adalah Program Studi Teknik Informatika S1, Program Studi Sistem Informasi S1, Program Studi Teknik Informatika D3, Program Studi Manajemen Informatika D3, dan Program Studi Desain Komunikasi Visual S1.

Salah satu syarat bagi mahasiswa di Fakultas Ilmu Komputer untuk lulus menyelesaian kuliahnya adalah dengan mengambil Skripsi. Skripsi adalah mata kuliah wajib yang memberikan pengalaman belajar kepada mahasiswa untuk membuat karya ilmiah tertulis dengan cara melakukan penelitian untuk memecahkan suatu masalah. Setiap mahasiswa yang mengambil mata kuliah Skripsi selalu diarahkan untuk membaca dan mencermati buku panduan Skripsi.

Buku panduan Skripsi merupakan salah satu media informasi proses Skripsi yang digunakan di Fakultas Ilmu Komputer. Media buku sebagai panduan Skripsi menjadi media tunggal dalam menyebarkan informasi mengenai panduan Skripsi. Media buku memiliki kekurangan sebagai media informasi panduan Skripsi, diantaranya adalah menjadi media yang kurang menarik untuk diperhatikan, masih sedikitnya mahasiswa yang menggunakan media buku sebagai media informasi untuk panduan Skripsi, pemahaman yang berbeda dari media buku, dan kesulitan dalam mengakses media buku sebagai panduan Skripsi.

Oleh karena itu, untuk menyelesaikan permasalahan tersebut maka diperlukan sebuah inovasi dalam pengembangan aplikasi multimedia panduan Skripsi menggunakan adobe flash CS.6. Diharapkan dengan adanya aplikasi tersebut dapat menarik dan mempermudah mahasiswa dalam mencari informasi mengenai panduan Skripsi di Fakultas Ilmu Komputer Universitas Kuningan.

Berdasarkan latar belakang masalah diatas, maka peneliti dapat merumuskan permasalahan sebagai berikut:

1. Bagaimana merancang dan membuat aplikasi multimedia panduan Skripsi menggunakan adobe flash CS6?

2. Bagaimana langkah-langkah dalam proses pembuatan aplikasi multimedia panduan Skripsi?

3. Bagaimana menggunakan aplikasi multimedia panduan Skripsi dengan baik dan mudah?

Batasan masalah dari penelitian ini adalah sebagai berikut:

1. Aplikasi multimedia panduan Skripsi ini dibuat dengan menggunakan software Adobe Flash CS6.

2. Aplikasi multimedia panduan Skripsi ini meliputi persyaratan Skripsi, Tata cara pengajuan judul Skripsi, proses bimbingan Skripsi dan sidang Skripsi.

3. Metodologi yang digunakan dalam penelitian ini adalah RUP (Rational Unified Process).

4. Metode pengumpulan data yang digunakan adalah metode observasi, wawancara dan studi pustaka.

Diharapkan hasil dari penelitian ini dapat menghasilkan sebuah aplikasi. Adapun tujuan penelitian yang ingin dicapai adalah sebagai berikut:

1. Untuk membuat sebuah aplikasi multimedia panduan Skripsi menggunakan software Adobe Flash CS6.

2. Untuk membuat inovasi media panduan Skripsi berbasis multimedia yang mudah digunakan dan menarik.

3. Untuk menerapkan metode RUP (Rational Unified Process) dalam pembuatan aplikasi multimedia panduan Skripsi. 


\section{METODE PENELITIAN}

Tahap perancangan sistem dalam penelitian ini menggunakan pemodelan UML (Unified Modelling Language). UML merupakan bahasa standar yang digunakan untuk menjelaskan dan memvisualisasikan rancangan proses analisis dan desain berorientasi objek.

Use Case Diagram mendeskripsikan sistem/aplikasi, lingkungan dan relasi antara sistem/aplikasi dengan lingkungannya. Dalam aplikasi yang dibuat, aktor memiliki beberapa perlakuan umum yang dapat dilakukan.

Use Case Diagram menggambarkan pengguna dengan aplikasi. Pada gambar 1 dapat kita lihat use case diagram untuk penelitian ini.

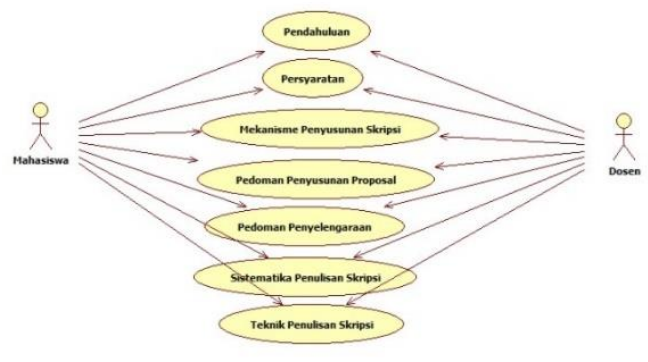

Gambar 1.Use Case awal aplikasi

Use Case diatas menggambarkan 2 aktor yaitu mahasiswa dan dosen, yang dimana pengguna dapat memilih Pendahuluan, Persyaratan, Mekanisme Penyusunan Skripsi, Pedoman Penyusunan Proposal, Pedoman Penyelenggaraan, Sistematika Penulisan Skripsi, dan Teknik Penulisan Skripsi.

Gambar 2 merupakan alur pemrosesan Activity Diagram menu utama.

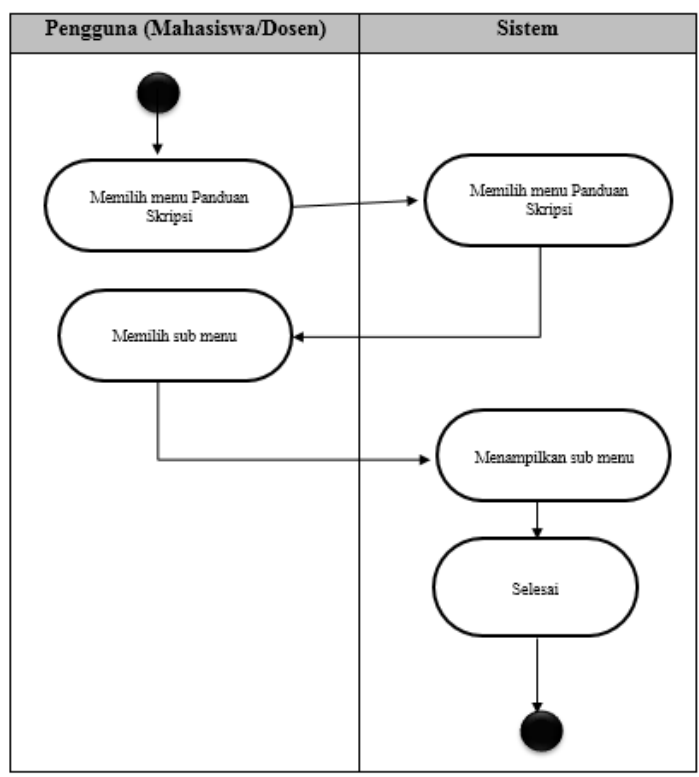

Gambar 2.Activity diagram Menu Utama

Gambar 3 merupakan gambar class diagram aplikasi.

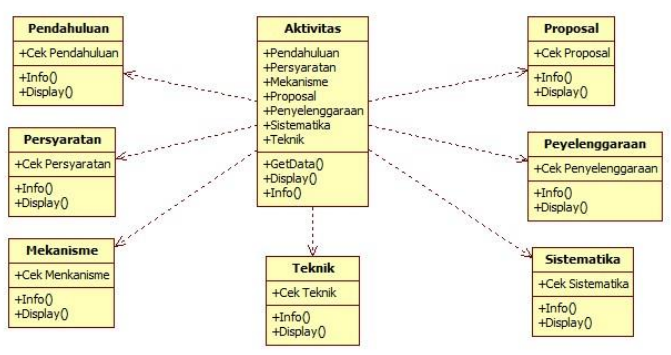

Gambar 3. Class Diagram Aplikasi

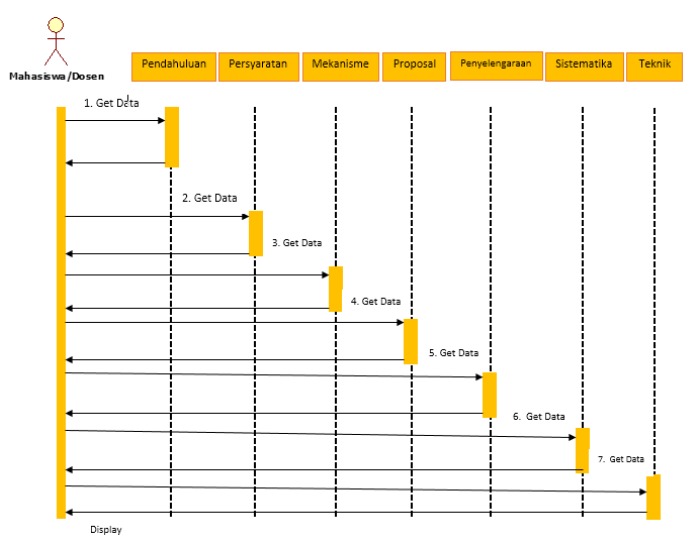

Gambar 4. Sequence Diagram Aplikasi 
Proses selanjutnya, setelah dibuat class diagram adalah membuat sequence diagram. Sequence diagram digunakan untuk menggambarkan skenario atau rangkaian langkah-langkah yang dilakukan sebagai sebuah respon dari suatu kejadian untuk menghasilkan output. Adapun sequence diagram yang dirancang dari aplikasi ini digambarkan pada Gambar 4

Setelah tahapan Inception dan Elaboration dilakukan, maka selanjutnya akan dilakukan tahapan Construction dan Transition. Pada tahapan Construction akan lebih fokus pada hasil perancangan tampilan dan menu-menu yang diusulkan. Sementara itu, pada tahapan Transition lebih fokus pada proses pengujian dari aplikasi yang dirancang.

\section{HASIL DAN PEMBAHASAN}

Setelah mengalami sederetan proses iterasi, pada tahapan Construction ini sudah dapat menghasilkan suatu aplikasi. Halaman tampilan utama merupakan halaman awal yang pertama kali muncul ketika aplikasi dijalankan. Gambar 5 merupakan hasil dari halaman intro.

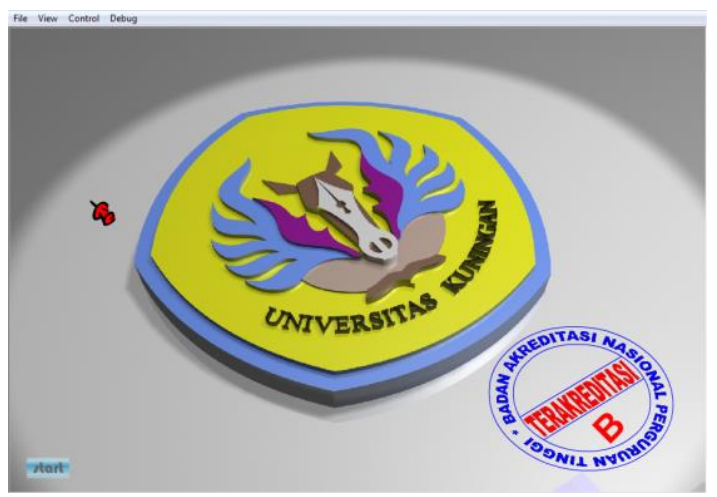

Gambar 5. Tampilan Intro

Halaman animasi loading ini merupakan halaman sebelum masuk kedalam aplikasi. Halaman animasi ini digunakan oleh user. Gambar 6. menggambarkan hasil dari pembuatan halaman animasi.

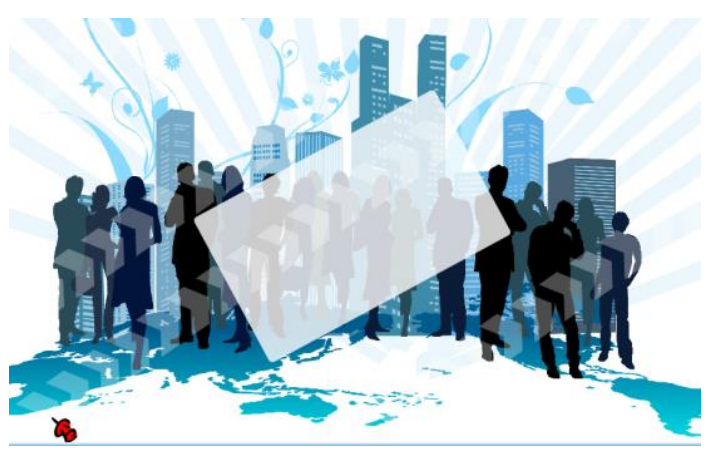

Gambar 6. Tampilan Menu File

Halaman ini merupakan halaman utama dari aplikasi panduan Skripsi. Pada halaman menu utama ini terdapat enam buah list pilihan untuk user. Pilihan yang dapat ditentukan oleh user adalah Pendahuluan, Persyaratan, Mekanisme, Pedoman, Sistematika, dan Teknik. Gambar 7 merupakan gambar tampilan menu utama setelah user melalui proses start

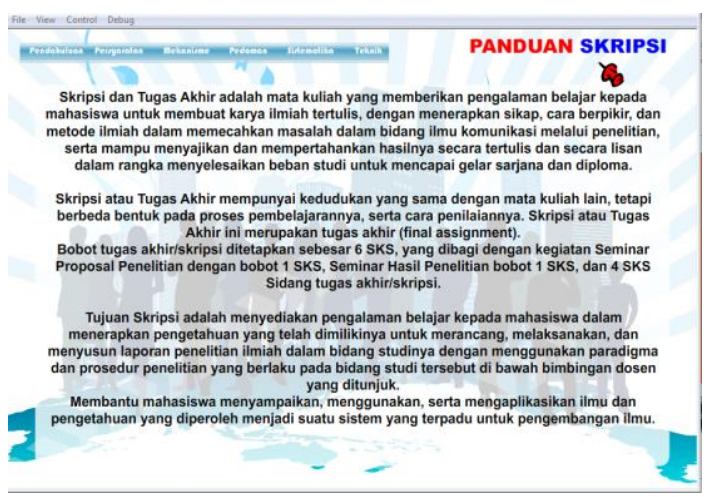

Gambar 7. Tampilan Menu Utama

Gambar 8 merupakan gambaran halaman menu persyaratan.

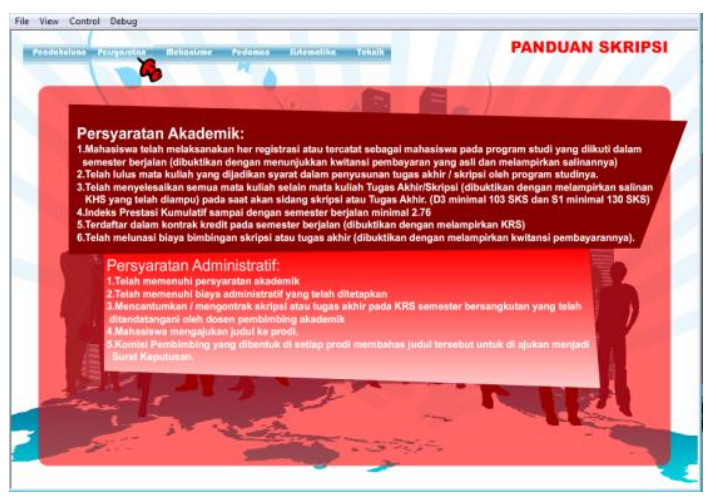

Gambar 8. Tampilan Menu Persyaratan 
Pada halaman Mekanisme berisi tentang prosedur-prosedur yang harus dilalui oleh calon mahasiswa dalam mengambil Skripsi. Gambar 9 merupakan tampilan dari halaman Mekanisme.

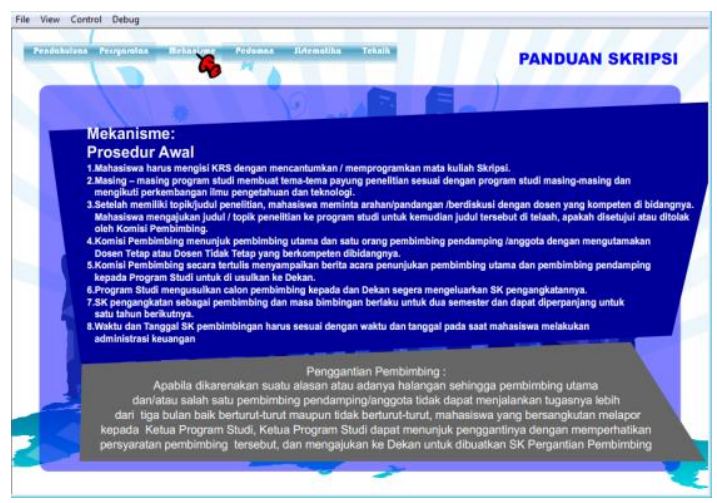

\section{Gambar 9. Halaman Mekanisme}

Tahap Transition merupakan tahapan akhir dari proses RUP. Dalam tahapan ini lebih difokuskan pada masalah pengujian. Proses pengujian sendiri memiliki banyak jenis. Proses pengujian adalah proses mengeksekusi aplikasi untuk menentukan apakah apliaksi perangkat lunak tersebut cocok dengan spesifikasi sistem dan berjalan sesuai dengan lingkungan yang diinginkan.

Tahap pengujian merupakan elemen kritis dari kualitas aplikasi perangkat lunak yang telah dibangun dan mempresentasikan kajian pokok dari spesifikasi, perancangan dan proses pengkodean.

Pengujian Black Box adalah proses pengujian aspek fundamental aplikasi tanpa memperhatikan struktur logika internal perangkat lunak. Proses pengujian ini dilakukan untuk mengetahui apakah aplikasi perangkat lunak dapat berjalan dan berfungsi dengan benar.

Pengujian black box merupakan suatu metode perancangan data uji yang didasarkan pada spesifikasi perangkat lunak. Hasil keluaran dari aplikasi perangkat lunak dicek apakah telah sesuai dengan yang diharapkan. Proses pengujian black box dilakukan pada Menu. Adapun hasil pengujian Black Box yang telah dilakukan pada Menu File bagian Masukan Citra dapat dilihat pada Tabel 1.
Tabel 1. Hasil Pengujian Black Box

\begin{tabular}{|c|c|c|c|c|}
\hline No & $\begin{array}{c}\text { Fungsi yang } \\
\text { di uji }\end{array}$ & Cara Menguji & $\begin{array}{l}\text { Hasil yang } \\
\text { diharapkan }\end{array}$ & $\begin{array}{c}\text { Hasil yang } \\
\text { keluar }\end{array}$ \\
\hline 1 & Cek Loading & $\begin{array}{l}\text { User melakukan } \\
\text { Loading ke aplikasi } \\
\text { dengan menjalankan } \\
\text { aplikasi }\end{array}$ & $\begin{array}{ll}\text { Tampil Menu } \\
\text { Utama }\end{array}$ & \begin{tabular}{|l|} 
Sesuai \\
dengan \\
harapan \\
Valid
\end{tabular} \\
\hline 2 & Cek Menu & $\begin{array}{l}\text { User melakukan klik } \\
\text { menu Persyaratan }\end{array}$ & $\begin{array}{l}\text { User dapat } \\
\text { berpindah } \\
\text { halaman } \\
\text { persyaratan }\end{array}$ & $\begin{array}{l}\text { Sesuai } \\
\text { dengan } \\
\text { harapan } \\
\text { Valid } \\
\end{array}$ \\
\hline 3 & Cek Menu & $\begin{array}{l}\text { User melakukan klik } \\
\text { menu Mekanisme }\end{array}$ & $\begin{array}{l}\text { User dapat } \\
\text { berpindah } \\
\text { halaman } \\
\text { Mekanisme }\end{array}$ & $\begin{array}{l}\text { Sesuai } \\
\text { dengan } \\
\text { harapan } \\
\text { Valid }\end{array}$ \\
\hline 4 & Cek Menu & $\begin{array}{l}\text { User melakukan klik } \\
\text { menu Pedoman }\end{array}$ & $\begin{array}{l}\text { User dapat } \\
\text { berpindah } \\
\text { halaman } \\
\text { pedoman }\end{array}$ & \begin{tabular}{|l|} 
Sesuai \\
dengan \\
harapan \\
Valid \\
\end{tabular} \\
\hline 5 & Cek Menu & $\begin{array}{l}\text { User melakukan klik } \\
\text { menu Sistematika }\end{array}$ & $\begin{array}{l}\text { User dapat } \\
\text { berpindah } \\
\text { halaman } \\
\text { sistematika }\end{array}$ & $\begin{array}{l}\text { Sesuai } \\
\text { dengan } \\
\text { harapan } \\
\text { Valid } \\
\end{array}$ \\
\hline
\end{tabular}

\section{KESIMPULAN}

Media aplikasi multimedia panduan Skripsi menggunakan Adobe Flash CS6. Berdasarkan hasil implementasi dan pembahasan yang telah dilakukan, maka dapat ditarik kesimpulan sebagai berikut.

1. Dengan adanya media aplikasi multimedia panduan Skripsi menggunakan Adobe Flash CS6 ini dapat menjadi sebuah media panduan alternatif dalam menyusun Skripsi.

2. Dengan adanya media aplikasi multimedia panduan Skripsi menggunakan Adobe Flash CS6 ini mahasiswa dapat mencari informasi dengan cara yang menarik dan berbeda.

3. Aplikasi dapat berjalan di komputer/nootbook yang telah terinstal flashplayer.

\section{SARAN}

Sesuai dengan permasalahan yang ada dan setelah perancangan aplikasi ini selesai, maka diberikan beberapa saran yang dapat digunakan dalam pengembangan aplikasi di 
masa mendatang. Adapun saran yang ingin disampaikan yaitu sebagai berikut.

1. Dibutuhkan media penyimpanan data yang besar dan fleksibel.

2. Dibutuhkan kerjasama tanya jawab dengan pihak-pihak yang mempunyai keahlian dalam bidang desain grafis, agar dalam proses pembuatan aplikasi bisa berjalan dengan lebih menarik dan baik.

3. Dibutuhkan banyak gambar untuk membuat tampilan lebih dinamis dan menarik.

\section{DAFTAR PUSTAKA}

Al Fatta, H. (2007). Analisis dan Perancangan Sistem Informasi untuk Keunggulan Bersaing Perusahaan dan Organisasi Modern. Yogyakarta : CV. Andi Offset.

Amir F. Sofyan, 2005. Modul Multimedia. Yogyakarta : STMIK AMIKOM Yogyakarta.

Amir F. Sofyan, 2006. Modul Multimedia TI. Yogyakarta : STMIK AMIKOM Yogyakarta.

Darmawan Erico, H. (2006). "Perancangan Mini Image Editor Versi 1.0 sebagai aplikasi Penunjang Mata Kuliah Digital Image Processing". Volume 2(2), 10 Halaman.

M. Suyanto, 2003. Multimedia Alat Untuk Meningkatkan Keunggulan Bersaing. Yogyakarta : Andi Offset.

M. Suyanto, 2004. Analisis dan Desain Aplikasi Multimedia Untuk Pemasaran. Yogyakarta : Andi Offset.

M. Suyanto, 2006. Merancang Film Kartun Kelas Dunia. Yogyakarta : Andi Offset.
Munir, R. (2004). Pengolahan Citra Digital Dengan Pendekatan Algoritmik. Bandung : Informatika.

Nugroho, Adi. 2005. "Analisis dan Perancangan Sistem Informasi dengan Metodologi Berorientasi Objek". Bandung: Informatika.

Putra, D. (2009). Pengoahan Citra Digital, Yogyakarta : C.V ANDI OFFSET.

Rosa-Shalahuddin, A. S. M. 2013. Rekayasa Perangkat Lunak Terstruktur dan Berorientasi Objek. Bandung : Informatika.

Ruslan, R. (2003). Metode Penelitian PR dan Komunikasi. Jakarta : PT Raja Grafindo Persada.

Septian, D. (2010). Implementasi Kebijakan Peraturan Pemerintah Nomor 98 Tahun 2000 Tentang Pengadaan Pegawai Negeri Sipil Di Badan Cianjur. Bandung. Universitas Komputer Indonesia.

\section{Biodata Peneliti}

Tito Sugiharto,memperoleh gelar Sarjana Komputer (S.Kom), Jurusan Teknik Informatika STMIK AMIKOM Yogyakarta, lulus tahun 2008. Memperoleh gelar Magister Enggineering (M.Eng) Program Pasca Sarjana Magister Teknologi Informasi Universitas Gajah Mada Yogyakarta, lulus tahun 2014. Saat ini menjadi Dosen di Universitas Kuningan Jawa Barat. Saat ini juga menjabat sebagai Kaprodi S1 Teknik Informatika Fakultas Ilmu Komputer di Universitas Kuningan. 